\title{
Inline tool wear measurement in lateral micro upsetting
}

\author{
Joseph Seven ${ }^{1, *}$, Lukas Heinrich ${ }^{1}$, Hendrik Flosky ${ }^{2}$ \\ ${ }^{1}$ BIAS GmbH, Klagenfurter Strasse 5, Bremen, Germany \\ ${ }^{2}$ Former: BIAS GmbH, Klagenfurter Strasse 5, Bremen, Germany
}

\begin{abstract}
Micro metal parts are usually produced in large lot sizes at high production rates. In order to achieve sufficient product quality, excessive tool wear has to be avoided. Conventional methodologies for tool wear measurement usually require tools to be disassembled and measured separately. Since accuracy of handling and assembly is limited in micro range, a reproducible tool positioning between measurements cannot be guaranteed. Therefore, analysis of tool wear development is hardly possible using conventional methods. In this study, an inline tool wear measurement methodology is investigated. Instead of measuring the tool itself, it is based on the measurement of the forming product. Therefore, lateral upsetting experiments on 1.4301 stainless steel wires with a diameter of $0.3 \mathrm{~mm}$ are carried out on a micro forming press. The indentation geometry on the wire is measured optically and compared to the tool geometry. It is shown that both are in good agreement for different states of tool wear and that features with geometrical characteristics above $2 \mu \mathrm{m}$ are transferred onto the indentation surface. Thus, the investigated methodology presents a feasible way for inline tool wear measurement.
\end{abstract}

Keywords: Micro forming, Cold forming, Wear

\section{Introduction}

The demand of micro parts in the areas consumer electronics, communication and in medicine technology increases continuously [1]. Products like smart phones become lighter and thinner while the quantities become higher. The sales of smart phones increased from 2013 with 969 million pieces [2] to 1.537 billion pieces in 2017 [3]. These products contain micro parts which have to be manufactured in a fast and cost efficient production [4]. A preferably high tool life is essential to increase the quantity and reduce the production costs. One approach to increase the tool life is the improvement of the tool wear. So a characterisation of the tool wear is required to identify the wear mechanisms and to improve in a following step the wear behaviour.

Especially in micro range the accuracy of handling and assembly is more difficult than in macro range. A dismounting and mounting of the micro tool can result in positioning errors. Therefore, to assure a reliable tool measurement, the tool has to be measured without removing it from the press.

Micro tools can be used for the production of micro parts in a combined blanking and deep drawing process [5]. In this case the outer diameter of a micro blanking and deep drawing die was decreased through a wrong positioning. The contact between the tool and the tool guide became bigger resulting in a stronger abrasion. A method which can be used for the tool wear measurement is the measurement of negative indentations [6]. Here the geometry of the tool is transferred in silicon with an accuracy of less than $1 \mu \mathrm{m}$ but the production has to be stopped for that indentation. Another technique offers the comparative digital holography with an inline technique due to the accessibility of that measurement setup [7]. The holographic measurement setup is integrated into the press so that the micro tool can be measured inline.

In contrast of measuring the tool itself the forming product can be measured as well to analyse the tool wear. In this paper lateral upsetting experiments in micro cold forming are used to form a $0.3 \mathrm{~mm}$ thin wire in a micro forming press. The advantages for this method are no dismounting and mounting of the tool, lower downtimes and better accessibility. Both the geometry of the indentation and the tool geometry are measured and compared to each other by a laser scanning microscope. The goal is to show the feasibility of this method for an inline tool measurement.

\section{Method}

\subsection{Lateral micro upsetting}

Lateral upsetting experiments on 1.4301 stainless steel wires with a diameter of $0.3 \mathrm{~mm}$ were carried out on a highly dynamic micro forming press [8]. The machine axes are driven by electrical linear motors with a

\footnotetext{
Corresponding author: seven@bias.de
} 
maximum acceleration of $10 \mathrm{~g}$ and a maximum velocity of $3.2 \mathrm{~m} / \mathrm{s}$. The positioning error is below $3 \mu \mathrm{m}$ at maximum acceleration and the repeat positioning error is below $1 \mu \mathrm{m}$ up to a stroke of $8 \mathrm{~mm}$. Fig. 1 shows a near overview of the forming process. The forming punches are made of HSS and mounted to the tool holder. The tool holder is linked axial to a piezo force sensor, type Kistler 9311B, which has an accuracy of $0.01 \mathrm{~N}$. The forming force $F_{U}$ is monitored for each sample with a frequency of $5 \mathrm{kHz}$. The wire is feed through the guide and positioned by a feed system (Zehnder und Sommer EDV 040 - 220 DG). To find the contact point between wire and punch the punch was driven manually until a pre-load force of $\sim 10 \mathrm{~N}$ was monitored. This point was used as the contact point in the automatically experiments. The counter plate is made of case hardened steel $(\mathrm{C} 15)$ and mounted beneath the guide.

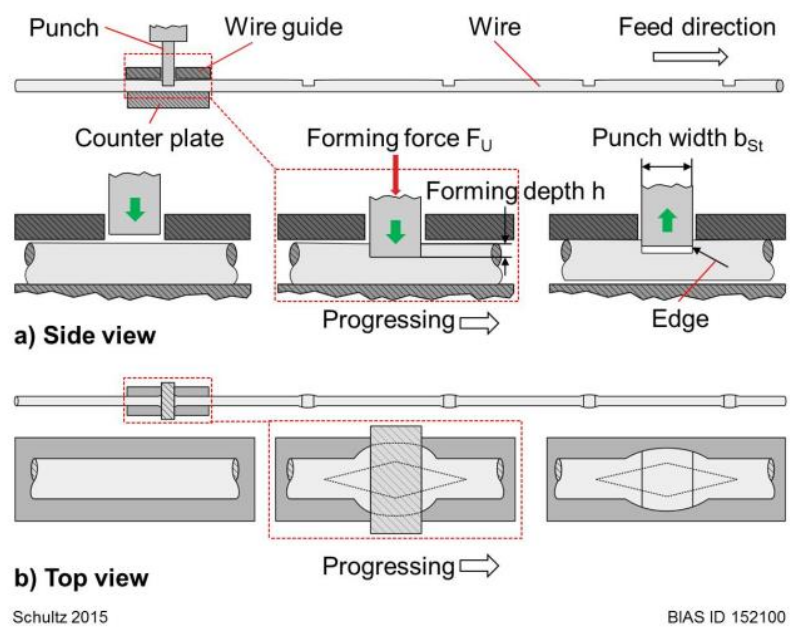

Fig. 1. Schematic view of the lateral upsetting process

Fig. 1 shows one stroke of the forming process in three steps schematically, a.) side view and b.) top view. In the first state (left) the wire is positioned by the feed system below the punch, without any contact between wire and punch. In the second step the punch moves downwards and penetrates the wire to a defined depth of $h$. Before the punch contacts the wire the force measuring system starts to monitor the force. The wire is deformed elastically and plastically and material freely flows to the sides as well as in wire direction. The deformed wire has typically the form of a rhombus, as shown in the middle and on the left side of the top view. When the wire is stripped of from the punch the elastic deformation reverts. At the end (step 3) the punch moves upwards to the starting position and the process starts again with a production rate of 350 strokes per minute. Table 1 shows the process and geometric parameters.

Table 1. Geometries, materials and process parameters for lateral upsetting

\begin{tabular}{cc}
\hline punch width & $0.50 \mathrm{~mm}$ \\
wire thickness & $0.30 \mathrm{~mm}$
\end{tabular}
forming velocity
$18 \mathrm{~mm} / \mathrm{s}$
penetration depth
$0.15 \mathrm{~mm}$
tool material
HS 6-5-2
wire material
X5CrNi18-10
counter plate
C15 (case hardened)
lubricant
none

\subsection{Analysis}

The surface measurements of the tool and the wire are done by an optical and contact-free 3D laser scanning microscope (Keyence VK-9710). Depending on the number of strokes surface measurements were done on both parts.

\section{Results}

Fig. 2 shows a comparison of the tool and wire surface. The punch penetrated the wire with 300000 strokes, a penetration depth of $150 \mu \mathrm{m}$ and a forming velocity of $18 \mathrm{~mm} / \mathrm{s}$.
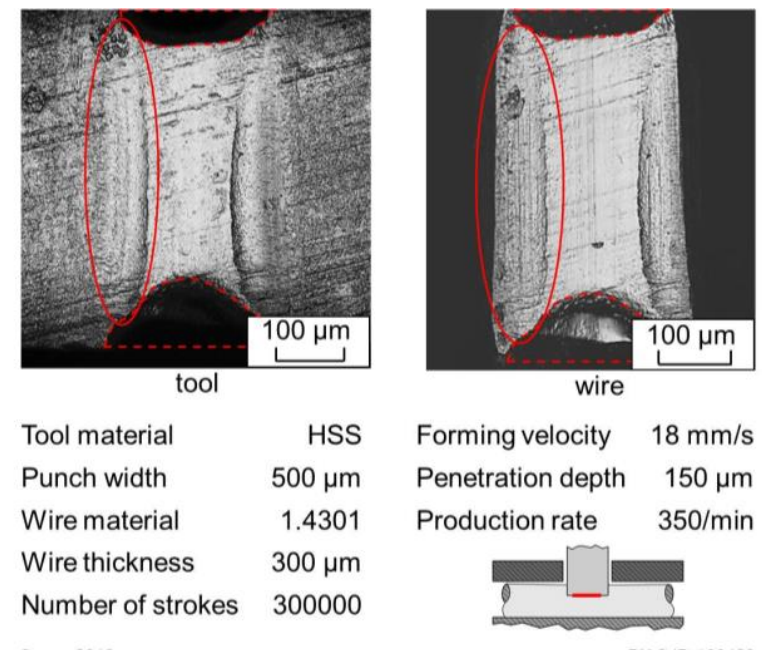

Forming velocity $18 \mathrm{~mm} / \mathrm{s}$ Penetration depth $150 \mu \mathrm{m}$ Production rate $\quad 350 / \mathrm{min}$

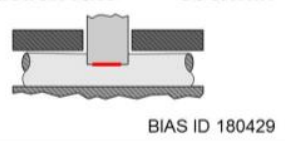

Fig. 2. Comparison of surfaces between tool (left) and wire (right) after 300000 strokes

On the punch surface (Fig.2, left) there are two parallel traces visible (red circles). The two traces of the punch are impressed in the wire which can be seen on the microscopic picture (Fig. 2, right). Furthermore on the dashed red lines in the pictures tool wear can be seen on the punch edges

To measure the tool wear the wire geometry is optically analysed and compared to the tool geometry. For that on both microscopic pictures (tool and wire) similar profile lines were chosen which were orientated through the sanding marks of the surface. Along these profile lines height profiles were created for both components. Both 
height profiles were fitted and compared related to height differences (see in Fig. 3). The pictures were created with a 20x magnification, a z-pitch of $0.1 \mu \mathrm{m}$ and a xy-resolution of $346 \mathrm{~nm}$.

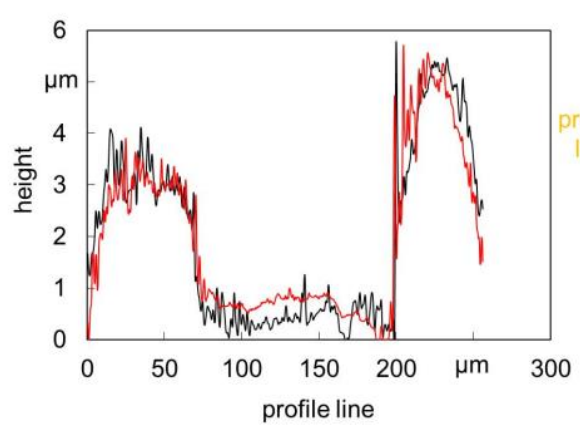

Tool material

Punch width

Wire material

Wire thickness

Seven 2018

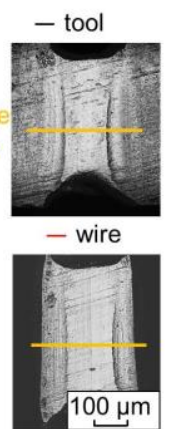

$18 \mathrm{~mm} / \mathrm{s}$

$150 \mu \mathrm{m}$

$350 / \mathrm{min}$

300000 BIAS ID 180430
Fig. 3. Fit of height profiles of tool and wire along similar profile lines

The difference in the height profiles of the tool and wire is determined and averaged over the profile line. In Fig. 4 height difference for an exemplary profile line is shown. With the exception of three peaks around $200 \mu \mathrm{m}$ the height difference is below $1.5 \mu \mathrm{m}$. The average over the profile line is $0.45 \mu \mathrm{m}$ with a standard deviation of $0.43 \mu \mathrm{m}$.

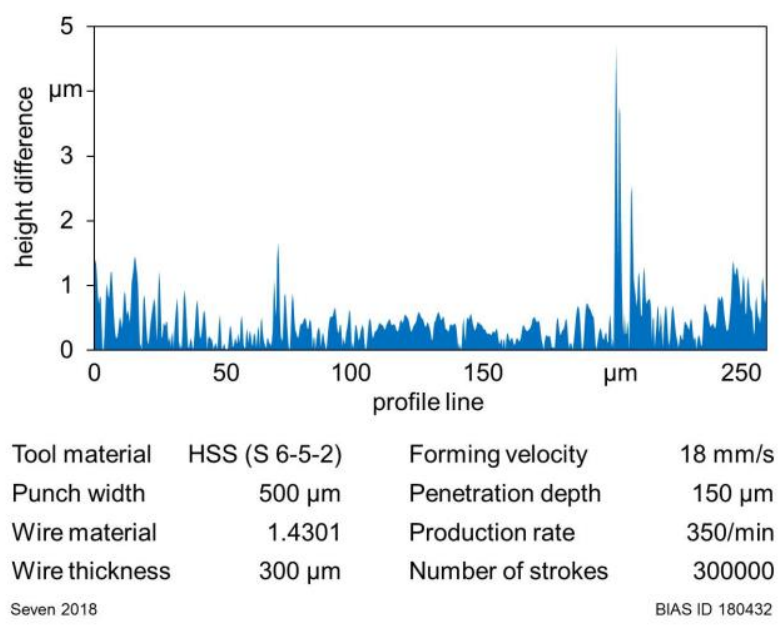

Fig. 4. Difference between the height profiles of tool and wire

The determination of the averaged height difference is done for three different profile lines. That three averaged height differences are also arithmetically averaged. The result is defined as the forming accuracy. Fig. 5 shows the forming accuracies of two equal samples for several numbers of strokes. In both cases a punch manufactured with HSS is used on a wire of 1.4301.

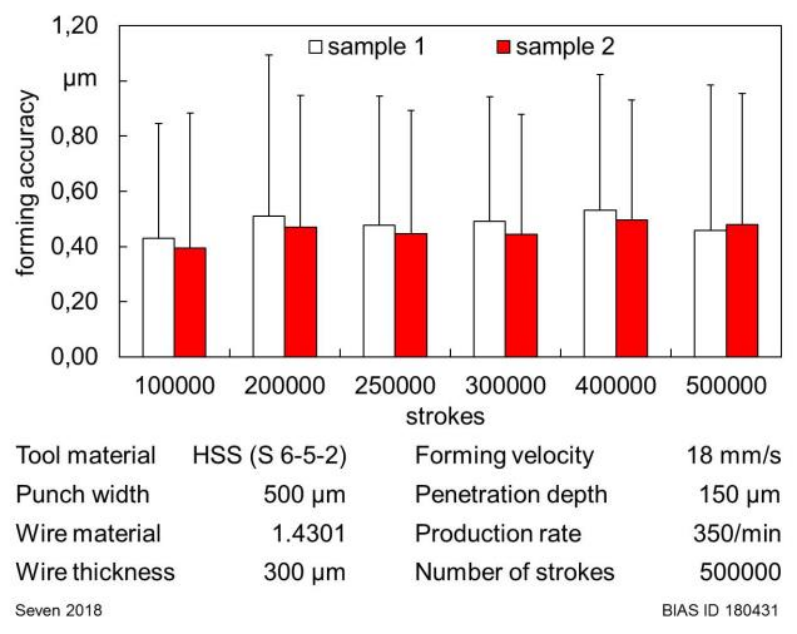

Fig. 5. Forming accuracy of the geometry of two equal punches HSS on the wire until 500000 strokes

The forming accuracy of each sample is similar for the number of strokes. The averages of the forming accuracies over the strokes are $0.48 \mu \mathrm{m}$ (sample 1) and $0.45 \mu \mathrm{m}$ (sample 2). The standard deviations are located between $0.42 \mu \mathrm{m}$ and $0.58 \mu \mathrm{m}$. The forming accuracy of both samples is for each number of strokes below $1.5 \mu \mathrm{m}$ by addition of average and standard deviation.

\section{Discussion}

The measurement surfaces show two parallel traces on the punch and wire. By penetration of the punch the wire material flows to the sides where both traces occur through abrasion. The punch edges show a stronger wear. This may be affected by a higher normal force on the punch edges than on the front surface.

The forming accuracies depending on the number of strokes are similar. That means that different high tool wear can be measured. Moreover the results between sample 1 and sample 2 are similar. These similar results are indications for a reproducible measurement system.

The standard deviations of the forming accuracies range between $0.42 \mu \mathrm{m}$ and $0.58 \mu \mathrm{m}$ at mean forming accuracies around $0.5 \mu \mathrm{m}$. This may be influenced by the inaccuracies during the fitting of the height profiles (see in Fig. 6). Both height profiles are shown with the corresponding height difference. Especially around $200 \mu \mathrm{m}$ there are three peaks (height difference). Both tool and wire show high height values in that area. One curve is displaced so that tool and wire are not exactly fitted which leads to extremely high standard deviations. 


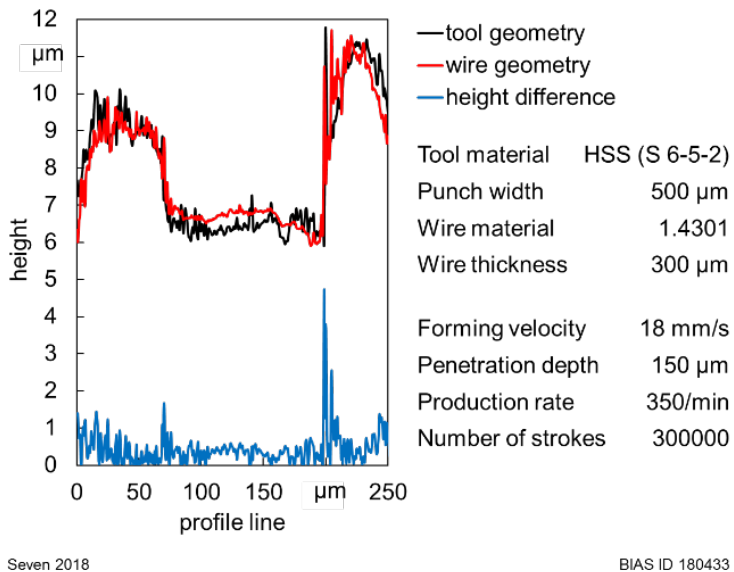

Fig. 6. Forming accuracy of the geometry of two equal punches HSS on the wire until 500000 strokes

The reason could be the elastic rear deformation of the wire. By removing the punch from the wire the elastic deformation of the wire reverts. Through the elastic rear deformation the wire geometry could be contracted and thus the peaks of tool and wire displaced.

In this example (Fig. 6) the averaged difference is $0.45 \mu \mathrm{m} \pm 0.43 \mu \mathrm{m}$. Without the three peaks around $200 \mu \mathrm{m}$ the value is changed to $0.41 \mu \mathrm{m} \pm 0.29 \mu \mathrm{m}$. Furthermore artefacts, which are contained in the surface measurements, lead to peaks in the height profiles and disturb the result.

Finally the tool wear can be analysed on the wire indentation with an accuracy of less than $1.5 \mu \mathrm{m}$. The advantage is no dismounting and mounting of the tool compared to other measurement methods like the negative indentation. The negative indentation in silicon can also be used for tool wear measurement with accuracies below $1 \mu \mathrm{m}$ [6], but the production has to be stopped for the silicone indentation. For the inline wear recording with the digital holography the production needs to be stopped as well [7]. However the inline tool wear measurement on the wire indentation offers an accurate measurement without stopping the production.

\section{Conclusion}

In lateral micro upsetting features of the punch are formed onto the forming product with an accuracy below $1.5 \mu \mathrm{m}$. Hence, assessment of tool wear can be done by analysing the forming product rather than the punch itself without stopping the production.

The authors gratefully acknowledge the financial support by Deutsche Forschungsgemeinschaft (DFG,German Research Foundation) for the Subprojects B3 Werkzeuglebensdauer and B7 Prozessstabilität within the SFB 747 (Collaborative Research Center) "Mikrokaltumformen - Prozesse, Charakterisierung, Optimierung".

\section{References}

1. M. Geiger, M. Kleiner, R. Eckstein, N. Tiesler and U. Engel, "Microforming," CIRP Annals Manufacturing Technology 50, pp. 445-462 (2001)

2. N.N., "Gartner Says Smartphone Sales Surpassed One Billion Units in 2014,” (2015) [Online]. Available: https://www.gartner.com/newsroom/id/2996817. [Accessed 1804 2018].

3. N.N., "Gartner Says Worldwide Sales of Smartphones Recorded First Ever Decline During the Fourth Quarter of 2017," (2018) [Online]. Available: https://www.gartner.com/newsroom/id/3859963. [Accessed 1804 2018].

4. H. Hoffmann, "Tensile Test of very thin Sheet Metal and Determination of Flow Stress Considering the Scaling Effect," CIRP Annuals Manufacturing Technology 55, pp. 263-266 (2006)

5. H. Flosky and F. Vollertsen, "Wear behaviour in a combined micro blanking and deep drawing process," CIRP Annals Manufacturing Technology 63, pp. 281-284 (2014)

6. H. Flosky, M. Krüger and F. Vollertsen, "Verschleißmessung in der Mikroumformung mittels Silikonabformverfahren an einem kombinierten Schneid-Ziehring," in Tagungsband 7. Kolloquium Mikroproduktion, Aachen (2015)

7. S. Huferath-von Lüpke and S. Bergmann, "Digital holography for inline wear recording on deep drawing tools," Proceedings of the 4th International Conference on Nanomanufacturing (nano-Man 2014) (2014)

8. H. Schulze Niehoff, Entwicklung einer hochdynamischen, zweifachwirkenden Mikroumformpresse, Dissertation, BIAS Verlag (2008) 